J. Lake Sci. (湖泊科学), 2011, 23(2): 174-182

http: //www.jlakes.org. E-mail: jlakes@niglas. ac.cn

(c) 2011 by Journal of Lake Sciences

\title{
基于双源蒸散和混合产流的分布式水文模型构建及应用一以辽河 老哈河流域为例
}

\author{
刘晓帆 ${ }^{1,2}$,任立良 ${ }^{2 * *}$, 徐 静 $^{3}$, 袁 $飞^{2}$ \\ (1:四川省交通厅交通勘察设计研究院,成都 610017) \\ ( 2 :河海大学水文水资源与水利工程科学国家重点实验室,南京 210098) \\ (3: 南京大学地球科学与工程学院水科学系, 南京 210093)
}

摘 要: 以北方半干早地区的辽河老哈河流域为研究对象, 采用网格离散化方法进行水文模拟单元划分, 利用具有物理 基础的双源蒸散发能力估算模型, 计算每个栅格单元的截留蒸发、植被蒸腾能力和土壤蒸发能力, 并取代蒸发血资料作 为混合产流模型的蒸散发能力输人, 从而构建基于双源蒸散与混合产流的分布式水文模型, 并对老哈河流域 $1970-1979$ 年的日径流过程进行模拟分析, 结果表明双源蒸散发能力计算模型能够考虑植被类型及其生理、物候特性对蒸散发能力 的影响,将其与混合产流模型进行嵌套构建的分布式水文模型能较合理地揭示研究区域的产汇流规律, 适用于该地区的 水文过程模拟.

关键词:蒸散发;混合产流;植被覆盖;半干旱区;老哈河流域

\section{Development and application of the distributed hydrologic model based on the two-source PET model and the hybrid runoff model: A case study of Laoha River catchment, Liaohe River Basin}

LIU Xiaofan ${ }^{1,2}$, REN Liliang ${ }^{2}$, XU Jing ${ }^{3} \&$ YUAN Fei ${ }^{2}$

(1: Sichuan Communication Surveying and Design Institute, Chengdu 610017, P. R. China)

(2: State Key Laboratory of Hydrology, Water Resources and Hydraulic Engineering, Hohai University, Nanjing 210098, P. R. China)

(3: Department of Hydrosciences, School of Earth Sciences and Engineering, Nanjing University, Nanjing 210093, P. R. China)

Abstract: The Laoha River catchment, Liaohe River Basin in the semi-arid region of northern China is selected for study. The interception evaporation, canopy transpiration and soil evaporation are computed by a physically-based two-source potential evapotranspiration model in each grid cell of the basin. The calculated potential evapotranspiration is regarded as the input of the hybrid runoff model instead of the pan evaporation. Then the grid-based distributed hydrologic model is built for daily runoff simulation during 1970 - 1979 in the target basin by coupling the two-source PET model in the hybrid runoff model framework. The results show that the two-source PET model can reflect the effects of vegetation type, vegetation physiological features and phonological characteristics on the evapotranspiration. And the grid-based distributed hydrologic model which can illuminate the rule of runoff generation and runoff routing is applicable for runoff simulation in the target basin.

Keywords: Evapotranspiration; hybrid runoff; land cover; semi-arid region; Laoha River catchment

我国北方地处生存环境脆弱多变的地区,干旱半干旱的范围约占国土总面积的 $40 \%$. 该地区降水量少、 植被相对稀疏、土地沙漠化严重, $80 \%$ 以上的降水都消耗于地表蒸散发. 因而对蒸散发这一主要水文要素进

* 国家重点基础研究发展计划 (973) 项目 (2006CB400502)、教育部和国家外专局高等学校学科创新引智计划项目 (B08048) 和教育部科学技术研究重大项目 (308012) 联合资助. 2010-05-22 收稿; 2010-07-05 收修改稿. 刘晓 帆,女, 1982 年生,博士;E-mail: liuxiaofanhhu@yahoo. com. cn.

** 通讯作者:E-mail: rll@ hhu. edu.cn. 
行精确计算,对半干旱区域的降雨径流计算、水资源评价及干旱评估中都有着重要的意义.

计算实际蒸散发的一种常用方法是先采用气象资料推求蒸散发能力,然后使用水文模型或陆面模式依 据土壤水分亏缺状况将蒸散发能力折算成实际蒸散发量 ${ }^{[1]}$. 在蒸散发能力估算方面, 蒸发血是用于估算蒸 散发能力最为常用的工具之一, 通常将蒸发血观测值与蒸发血经验系数相乘即为蒸散发能力 ${ }^{[2]}$. 蒸散发能 力也可以采用经验公式估算, 如 Penman 公式 ${ }^{[3]}$ 、基于辐射的 Priestley-Taylor 公式 ${ }^{[4]}$ 、基于温度的 BlaneyCriddle 公式 ${ }^{[5]}$ 等. 但是这些方法不能考虑植被类型,仅能计算水面蒸发量或采用简单的经验关系推求出作 物参照蒸发率 ${ }^{[6]}$. Penman-Monteith 公式 ${ }^{[7]}$ 能够弥补这些缺点, 它采用冠层阻抗来描述植物叶面气孔在部分 关闭情况下对蒸散发的影响. 然而 Penman-Monteith 公式采用了“大叶” 模型的假设,即潜热和感热通量的源 汇均在同一高度且温度相同. 这一假设仅适用于稠密植被或裸土表面, 不适用于稀疏植被 ${ }^{[8]}$. 因此很多学 者 ${ }^{[9-11]}$ 发展一系列双源模型来探讨稀疏植被的能量平衡和蒸散发过程. 这些模型基于能量平衡和空气动力 学原理将稀疏植被设定成由两个部分(植被和裸土) 构成的系统,采用阻抗网络来计算植被蒸腾和植被下土 层的蒸发量. 因此这些双源模型比“大叶”模型更适用于估算干旱、半干旱和稀疏植被农业区的蒸散发 能力 ${ }^{[8]}$.

本文针对研究区域老哈河流域的半干旱特征,将具有物理机制的双源蒸散发能力计算模型与混合产流 模型进行耦合,计算流域各处不同植被类型在整个生育期内的蒸散发能力,充分考虑流域植被覆盖的空间 差异性对蒸散发能力的影响,并显式地表征植被物侯特征、生理特性以及地形等因素对流域蒸散发、产流和 汇流过程的影响,在数字流域平台上利用 GIS 技术和遥感信息,构建具有一定物理机制的栅格型分布式水 文模型,对半干旱区域的水文过程进行模拟与分析.

\section{1 模型构建}

\section{1 双源蒸散发能力计算模型}

双源蒸散发能力计算模型将土壤和冠层作为两个相互独立又相互作用的源汇,分别对土壤表面和冠层 进行能量平衡计算,从而推导出蒸散发能力的计算公式. 模型中蒸散发能力 $(P E T)$ 由三部分构成: 截留蒸发 $\left(E_{i}\right)$, 即被雨水淋湿叶面上的截留雨水蒸发; 植被蒸腾能力 $\left(E_{\mathrm{pc}}\right)$, 即土壤含水量达到田间持水量时, 干燥植 被叶面气孔所散失的水分; 土壤蒸发能力 $\left(E_{\mathrm{ps}}\right)$, 即土壤含水量达到田间持水量时,裸土表面或冠层以下土 壤表面所散失的水分 ${ }^{[11]}$.

$E_{i}=\frac{\Delta R_{\mathrm{nc}}+\rho C_{\mathrm{p}} D_{0} r_{\mathrm{ac}}^{-1}}{\lambda(\Delta+\gamma)} W_{\mathrm{fr}}, E_{\mathrm{pc}}=\frac{\Delta R_{\mathrm{nc}}+\rho C_{\mathrm{p}} D_{0} r_{\mathrm{ac}}^{-1}}{\lambda\left[\Delta+\gamma\left(1+r_{\mathrm{cp}} r_{\mathrm{ac}}^{-1}\right)\right]}\left(1-W_{\mathrm{fr}}\right), E_{\mathrm{ps}}=\frac{\Delta\left(R_{\mathrm{ns}}-G\right)+\rho C_{\mathrm{p}} D_{0} r_{\mathrm{ac}}^{-1}}{\lambda\left[\Delta+\gamma\left(1+r_{\mathrm{sp}} r_{\mathrm{as}}^{-1}\right)\right]}$

式中, $R_{\mathrm{nc}}$ 为冠层净辐射 $\left(\mathrm{W} / \mathrm{m}^{2}\right) ; R_{\mathrm{ns}}$ 为土壤表面净辐射 $\left(\mathrm{W} / \mathrm{m}^{2}\right) ; G$ 为土壤热通量 $\left(\mathrm{W} / \mathrm{m}^{2}\right) ; \rho$ 为平均空气 密度 $\left(\mathrm{kg} / \mathrm{m}^{3}\right) ; C_{\mathrm{p}}$ 为空气比热 $\left(\mathrm{kJ} /\left(\mathrm{kg} \cdot{ }^{\circ} \mathrm{C}\right)\right) ; \Delta$ 为饱和水汽压梯度 $\left(\mathrm{kPa} /{ }^{\circ} \mathrm{C}\right) ; \gamma$ 为空气湿度常数; $\lambda$ 为蒸发 潜热 $(\mathrm{MJ} / \mathrm{kg}) ; W_{\mathrm{fr}}$ 为潮湿冠层比例; $r_{\mathrm{cp}}$ 为土壤含水量达到田间持水量时的冠层总气孔阻抗 $(\mathrm{s} / \mathrm{m}) ; r_{\mathrm{sp}}$ 为土 壤含水量达到田间持水量时的土壤表面阻抗 $(\mathrm{s} / \mathrm{m}) ; r_{\mathrm{ac}}$ 为冠层总边界层阻抗 $(\mathrm{s} / \mathrm{m}) ; r_{\mathrm{as}}$ 为土壤表面与冠层 源汇高度间的空气动力学阻抗 $(\mathrm{s} / \mathrm{m}) ; D_{0}$ 为冠层源汇高度处的水汽压 $(\mathrm{kPa})$.

采用上述公式进行蒸散发能力的计算时,首先利用美国马里兰大学全球 $1 \mathrm{~km}$ 土地覆被数据描述研究区 域植被类型的空间分布,采用 NOAA-AVHRR-NDVI 遥感数据反演研究区域叶面积指数的时空分布,然后基 于陆面数据同化系统 LDAS 和相关文献确定各类植被的参数 ${ }^{[12-13]}$, 利用辐射平衡和陆面阻抗参数化方案 ${ }^{[11]}$ 计算公式中的各净辐射项和阻抗项，从而获得各种植被覆被类型的蒸散发能力. 由于流域中除陆面覆被以 外,还存在各种类型的水体,因而,本文在原双源蒸散发能力计算模型的基础上增加了水面蒸发 $(E T)$ 的计 算 ${ }^{[2]}$, 以全面反映不同土地覆被类型对蒸散发能力计算的影响.

$$
E T=\frac{\Delta}{\Delta+\gamma} 0.048\left(R_{\mathrm{n}}-G\right)+\frac{\gamma}{\Delta+\gamma} 2.624\left(1+0.536 u_{2}\right)\left(e_{\mathrm{s}}-e_{\mathrm{a}}\right)
$$

式中, $e_{\mathrm{s}}$ 为饱和水汽压 $(\mathrm{kPa}) ; e_{\mathrm{a}}$ 为实际水汽压 $(\mathrm{kPa}) ; u_{2}$ 为 $2 \mathrm{~m}$ 高度处的风速 $(\mathrm{m} / \mathrm{s}), R_{\mathrm{n}}$ 为水面净辐射 $\left(\mathrm{W} / \mathrm{m}^{2}\right), G$ 为水体热通量 $\left(\mathrm{W} / \mathrm{m}^{2}\right)$. 


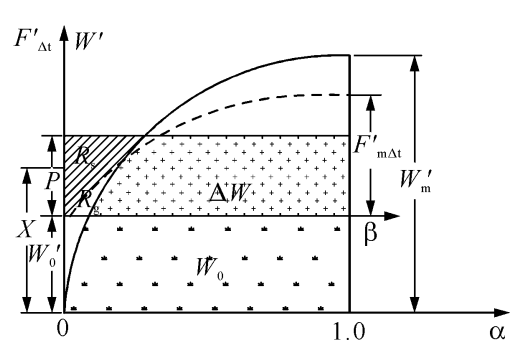

图 1 混合产流模块示意图

\section{2 产汇流模块}

1.2.1 混合产流 在半湿润地区和半干旱地区产流机制是很复杂 的, 尤其是在半干旱地区, 蓄满产流和超渗产流是交互发生的. 混 合产流模型将蓄满产流与超渗产流融为一体, 在一定程度上将两 种产流方式有机结合, 为半干旱、半湿润地区的水文模拟提供了一 种较为全面的产流方式. 李春红曾采用新安江模型、陕北模型和混 合产流模型对研究流域进行了水文模拟, 结果表明混合产流模型 优于上述两种单一的产流模型, 适合半干旱半湿润区的产流计 算 ${ }^{[14]}$. 该模型的基本结构见图 1 , 以 $\alpha$ 轴为横坐标轴的实线表示 Fig. 1 Sketch map of hybrid runoff module 流域蓄水容量曲线, 以 $\beta$ 轴为横坐标轴的虚线表示流域下渗能力 分布曲线. 流域蓄水容量分配曲线将流域划分为 $\alpha$ 与 $1-\alpha$ 两部 分, 在 $\alpha$ 部分面积上的降水全部产流, 其中包括因稳渗而产生的地下径流和因雨强超过下渗而产生的地面 径流, 而在 $1-\alpha$ 部分面积上, 降水过程中当土壤含水量达到田间持水量后才产流, 但在土壤含水量达到田 间持水量的过程中, 有时在未达到田间持水量的地方, 也会由于雨强大于下渗而产生地面径流; 流域下渗容 量分配曲线将流域划分为 $\beta$ 与 $1-\beta$ 两部分, 在 $\beta$ 部分面积上, 由于雨强大于下渗将产生地面径流, 而在 $1-$ $\beta$ 部分面积上不会因超渗而产流, 但当雨强很小, 在土壤含水量较高的地方也有可能因蓄满而产流. 模型中 流域蓄水容量分配曲线与新安江模型一致, 流域下渗容量分配曲线同样采用抛物线的形式进行表达, 并采 用霍顿下渗经验公式来计算流域平均下渗能力以及 $\Delta t$ 时段内的平均下渗容量.

对于一个特定的区域来说, 流域蓄水容量曲线是唯一的, 而下渗能力分布曲线不是唯一的, 它随着土壤 含水量的变化而变化. 因此对于不同的土壤含水量和降水量,两条曲线会相交在不同的区域或者不相交. 根 据流域蓄水容量曲线和下渗能力分布曲线是否存在交点, 可以分不同情况对产流量进行计算, 其具体计算 过程详见文献[14-15].

1.2.2 汇流模块进行坡地汇流时, 假设各栅格单元内均存在河道, 地表径流流速较快, 坡地汇流时间忽略 不计, 直接进人河网, 成为地表径流对河网的人流 ${ }^{[17]}$. 地下径流采用线性水库进行消退计算, 成为地下径流 对河网的人流, 最后单元面积河网总人流等于地表径流和地下径流之和. 从单元面积以下到流域出口是河 道汇流阶段. 河道汇流演算采用马斯京根分段连续演算法, 将栅格单元的河网总人流演算至流域出口断面 处,然后线性迭加成为流域出口断面处的流量过程.

\section{2 实例应用}

\section{1 老哈河流域概况}

老哈河流域 $\left(40.9^{\circ}-42.9^{\circ} \mathrm{N}, 117.2^{\circ}-120^{\circ} \mathrm{E}\right)$ 位于西辽河南源, 发源于河北省平泉县西北山区柳西川, 以小河沿水文站 $\left(42^{\circ} 26^{\prime} \mathrm{N}, 119^{\circ} 34^{\prime} \mathrm{E}\right)$ 为出口断面的流域面积为 $18599 \mathrm{~km}^{2} .1976$ 年以后小河沿水文站撤销, 在它上游新建的兴隆坡水文站 $\left(42^{\circ} 19^{\prime} \mathrm{N}, 119^{\circ} 26^{\prime} \mathrm{E}\right)$ 控制的集水区面积为 $18112 \mathrm{~km}^{2}$. 老哈河流域地势西南 高、东北低, 海拔高程自西南向东北由 $1836 \mathrm{~m}$ 降低到 $444 \mathrm{~m}$. 该流域内的生产方式以农业和畜牧业为主, 流域 内主要的植被类型为耕地和草地. 流域内有 10 个水文站, 52 个雨量站, 流域内及周边有 15 个气象站 (图 2a).

\section{2 资料准备}

本研究采用美国国家地球物理中心的全球 $1 \mathrm{~km}$ 基础高程资料 GLOBE (Global Land One-kilometer Base Elevation) 数据来描述老哈河流域的地形分布 (图 2b). 该 DEM 数据的空间分辨率为 $30 \mathrm{~s}$, 运用 DEDNM 模型 提取坡度和坡向等地形要素, 自动生成流域边界及水系 (图 2a), 为后续水文模拟提供数字流域平台基础. 采 用由中国科学院提供的 1980 年空间分辨率为 $30 \mathrm{~s}$ 的土地覆被资料数据产品来描述研究区域的土地利用/土 地覆被 LULC 分布. 利用美国国家航空航天局 NASA 的 Pathfinder AVHRR Land (PAL) 数据库提供的 NDVI 数据反演研究区域 LAI 的空间分布. 采用的气象资料来源于老哈河流域邻近的 15 个气象站,包括日平均气 温, 日最高、最低气温, $6 \mathrm{~h}$ 平均水汽压, 日平均风速, 日照时数; 所用的日降水资料来源于老哈河流域内甸子 
a

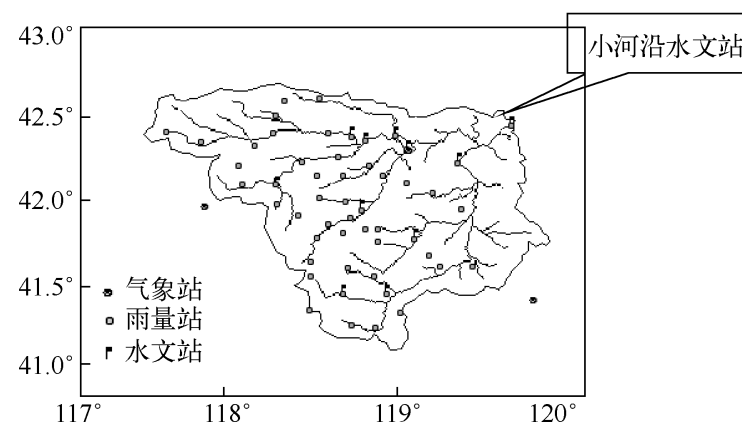

b

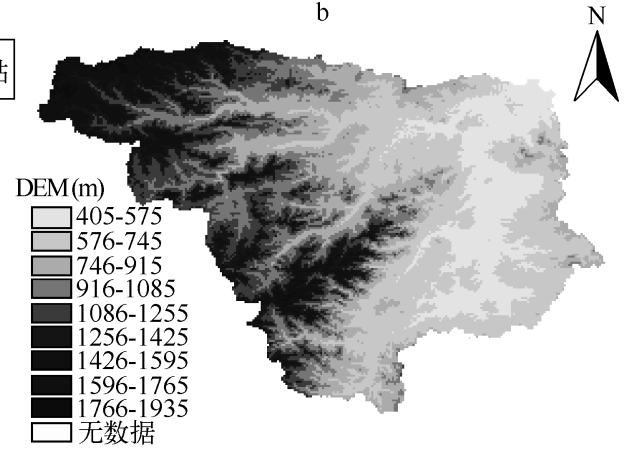

图 2 老哈河流域地理位置、测站和水系分布 (a) 及 DEM 空间分布 (b)

Fig. 2 Location, distribution of measurement stations, river network (a) and DEM map ( b ) of Laoha River catchment

等 52 个雨量站; 所用的日蒸发皿资料来源于老哈河流域内的甸子等 8 个水文站; 所用的流量资料来源于老 哈河流域内的小河沿等 10 个水文站. 采用遥感软件或基于反距离平方法将 NDVI 和水文气象数据处理为空 间分辨率为 $30 \mathrm{~s}$ 的数据空间展布.

\section{3 蒸散发能力计算}

本研究利用双源蒸散发能力计算模型计算了老哈河流域内 30577 个栅格单元 $1970-1979$ 年逐日蒸散 发能力. 通过建立蒸发血观测资料 (蒸发血的口径为 $20 \mathrm{~cm}$ ) 与其所在栅格单元的蒸散发能力之间的一元线 性回归模型以及进行皮尔逊相关分析来验证计算的蒸散发能力 $(P E T)$ 与蒸发血观测资料 $\left(E T_{\mathrm{pen}}\right)$ 在时间尺 度上的相似性和一致性, 从而检验蒸散发能力计算结果的合理性.

2.3.1 单点试验 7 个蒸发站的蒸发血. 日资料与其所在栅格单元计算的日蒸散发能力回归分析结果表明, 回归方程均通过了显著性水平 $\alpha=0.01$ 的 $F$ 检验 (表 1). 各回归方程的斜率均为正值, 相关系数均大于 0.74 , 这表明计算的日蒸散发能力与蒸发血日资料存在较好的正相关性,两者在时间尺度上具有较好的相 似性和一致性. 以太平庄站为例, 蒸发血日资料与计算的日蒸散发能力散点图及其回归分析结果见图 3. 由 于各站点所在栅格植被覆盖类型不同, 因而回归方程的截距和斜率存在差异, 同属耕地的甸子、太平庄、杨 树湾子和新井站的平均截距和斜率为 0.483 和 0.292 , 同属草地的西泉和初头朗蒸发站的平均截距和斜率 为 0.446 和 0.277 , 属于裸土 (滩地) 的小城子蒸发站的截距和斜率为 0.424 和 0.268 . 从这三种土地利用类 型来看, 耕地的日蒸散发能力较大, 其次为草地, 裸土 (滩地) 的蒸散发能力较小. 这说明具有物理机制的双 源蒸散发能力计算模型能够考虑植被类型对蒸散发能力的影响.

除了考虑植被类型会对蒸散发能力计算产生影响外, 植被生长季节性也会影响蒸散发能力的计算. 7 个 蒸发站蒸发血日资料与其所在栅格单元计算的日蒸散发能力在不同季节内回归分析结果表明 (表 2), 各回 归方程均通过了显著性水平 $\alpha=0.01$ 的 $F$ 检验. 以太平庄站为例, 蒸发血日资料与其所在栅格单元计算的 日蒸散发能力在不同季节内散点图及其回归分析结果见图 4. 各站点蒸发血日资料与其所在栅格单元计算 的日蒸散发能力的回归方程有着明显的季节性差异 (表 2). 春季, 地处我国北方的老哈河流域降水较少, 植 被刚开始生长, 陆面蒸散发能力主要是受到了气象因素的影响, 因此计算的日蒸散发能力与日蒸发血资料 相关性最好, 也就是说在春季利用蒸发血资料采用线性回归分析方法来推求陆面蒸散发能力是可行的. 夏 季, 老哈河流域降水丰沛, 植被生长茂盛, 影响陆面蒸散发能力的因素不仅有气象条件还有下垫面条件, 陆 面蒸散发能力中的植被截留受降水的影响较大, 而蒸发血资料没有考虑植被截留, 因而计算的日蒸散发能 力和日蒸发血资料的相关性较差, 这从侧面说明了双源蒸散发能力计算模型能够考虑植被生长状态对陆面 蒸散发能力的影响. 秋季, 老哈河流域降水减少, 植被生长开始出现衰退, 计算的日蒸散发能力与日蒸发血. 资料相关性较夏季好. 对比春季和秋季的回归方程可以看出, 秋季的回归斜率较春季高, 其原因在于尽管秋 
季植被生长出现衰退但其生长态势还是要好于春季, 在同样的气象条件下, 秋季的植被蒸腾和植被截留要 大于春季. 冬季, 老哈河流域温度降低, 降水较少, 植被枯萎, 因此计算的日蒸散发能力和蒸发血资料都较小 并且相关性也较好.

表 1 蒸发皿日资料与所在栅格单元日蒸散发能力回归分析

Tab. 1 Regression analysis on the daily pan evaporation and calculated PET

\begin{tabular}{ccccccc}
\hline 蒸发站 & 土地利用类型 & 截距 $b_{0}$ & 斜率 $b_{1}$ & 决定系数 $R^{2}$ & $F$ 值 & $P$ 值 \\
\hline 西泉 & 草地 & 0.416 & 0.276 & 0.599 & $F(1,2920)=4371.944$ & $<0.0005$ \\
甸子 & 耕地 & 0.508 & 0.308 & 0.570 & $F(1,3650)=4830.518$ & $<0.0005$ \\
小城子 & 裸土 & 0.424 & 0.268 & 0.618 & $F(1,3285)=5301.634$ & $<0.0005$ \\
太平庄 & 耕地 & 0.416 & 0.312 & 0.648 & $F(1,3650)=4391.537$ & $<0.0005$ \\
初头朗 & 草地 & 0.475 & 0.278 & 0.605 & $F(1,3650)=3738.500$ & $<0.0005$ \\
杨树湾子 & 耕地 & 0.468 & 0.308 & 0.542 & $F(1,2554)=2516.580$ & $<0.0005$ \\
新井 & 耕地 & 0.540 & 0.239 & 0.573 & $F(1,2554)=3423.020$ & $<0.0005$ \\
\hline
\end{tabular}

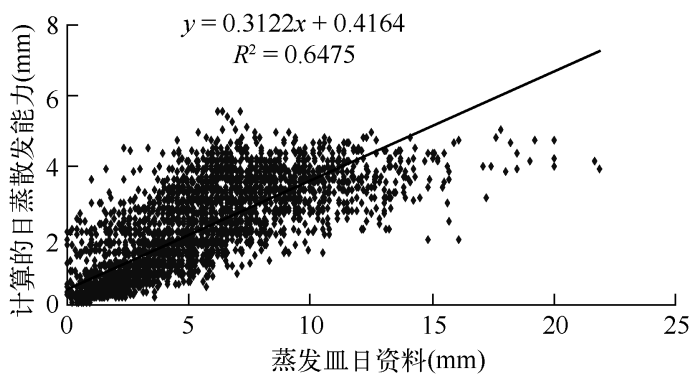

图 3 太平庄站蒸发血日资料与计算的日蒸散发能力散点图及其回归方程

Fig. 3 Scatter plots and regression equation of pan daily evaporation and calculated daily PET at Taipingzhuang station

表 2 蒸发血日资料与所在栅格单元日蒸散发能力在不同季节内回归分析

Tab. 2 Seasonal regression analysis on the daily pan evaporation and calculated PET

\begin{tabular}{|c|c|c|c|c|c|c|c|c|}
\hline \multirow{2}{*}{ 蒸发站 } & \multicolumn{2}{|c|}{ 春季(3-5 月) } & \multicolumn{2}{|c|}{ 夏季(6-8 月) } & \multicolumn{2}{|c|}{ 秋季 $(9-11$ 月 $)$} & \multicolumn{2}{|c|}{ 冬季( $12-2$ 月) } \\
\hline & 斜率 $b_{1}$ & 决定系数 $R^{2}$ & 斜率 $b_{1}$ & 决定系数 $R^{2}$ & 斜率 $b_{1}$ & 决定系数 $R^{2}$ & 斜率 $b_{1}$ & 决定系数 $R^{2}$ \\
\hline 西泉 & 0.218 & 0.764 & 0.112 & 0.388 & 0.310 & 0.524 & 0.129 & 0.389 \\
\hline 甸子 & 0.229 & 0.683 & 0.121 & 0.289 & 0.352 & 0.521 & 0.147 & 0.491 \\
\hline 小城子 & 0.197 & 0.657 & 0.204 & 0.466 & 0.231 & 0.404 & 0.149 & 0.439 \\
\hline 太平庄 & 0.233 & 0.698 & 0.153 & 0.401 & 0.353 & 0.632 & 0.172 & 0.534 \\
\hline 初头朗 & 0.201 & 0.619 & 0.172 & 0.388 & 0.294 & 0.453 & 0.161 & 0.358 \\
\hline 杨树湾子 & 0.213 & 0.692 & 0.148 & 0.340 & 0.332 & 0.453 & 0.181 & 0.633 \\
\hline 新井 & 0.172 & 0.687 & 0.096 & 0.263 & 0.281 & 0.480 & 0.122 & 0.321 \\
\hline
\end{tabular}

以上单点试验的结果充分表明蒸散发能力计算值与蒸发血观测资料在时间序列上具有较好的相似性 和一致性, 两者关系随季节和植被覆盖类型不同而变化, 因而在传统的水文模拟中, 仅采用一个蒸发折算系 数来描述二者之间的关系, 从而得到流域蒸散发能力的空间分布作为水文模型的输人, 会带来一定的误差. 2.3 .2 全流域试验 老哈河流域的年平均蒸散发能力空间分布差异性较大, 最小年平均蒸散发能力为 $455.8 \mathrm{~mm}$, 位于老哈河流域西北源头高海拔区; 最大年平均蒸散发能力为 $1280.6 \mathrm{~mm}$, 位于老哈河流域下游 河谷低海拔区 (图 5 ). 高海拔地区的气温较低, 蒸散发的大气需求较低, 而低海拔地区气温较高, 蒸散发较为 

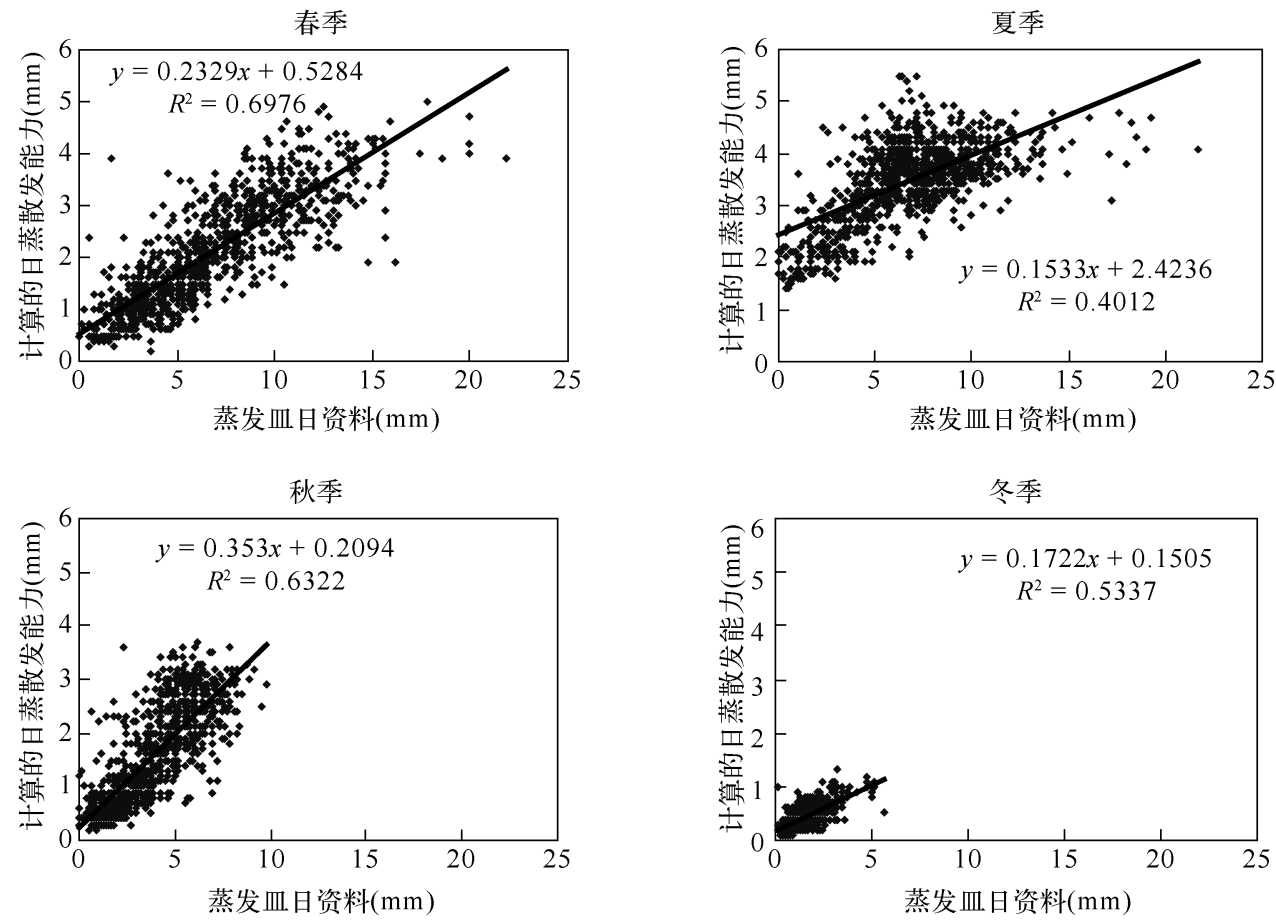

图 4 太平庄站蒸发血日资料与计算的日蒸散发能力在不同季节内散点图及其回归方程

Fig. 4 Scatter plots and regression equation of pan daily evaporation and calculated daily PET during different seasons at Taipingzhuang station
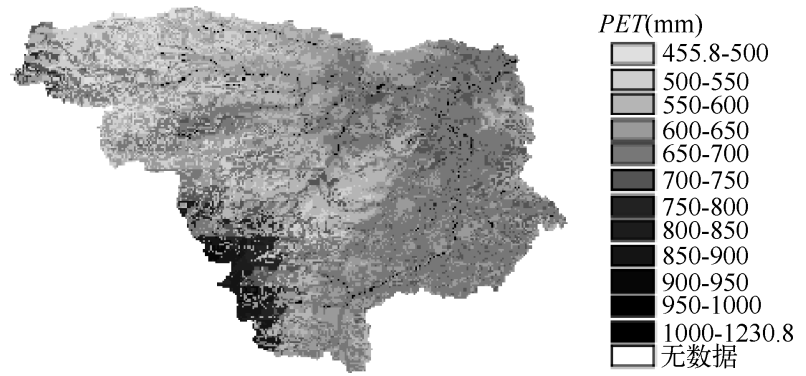

图 5 老哈河流域 $1970-1979$ 年均蒸散发能力空间分布

Fig. 5 Spatial distribution of the mean annual PET in the Laoha River catchment during 1970 - 1979

强烈,除了高程,土地利用的类型也是影响蒸散发能力空间分布的重要因素.计算老哈河流域内土地利用类 型相同栅格的蒸散发能力的算术平均值作为流域内该土地利用类型的多年平均蒸散发能力. 统计结果如 下: 老哈河流域水体、有林地、疏林地、密灌丛、灌丛、草地、耕地和裸土的年平均蒸散发能力分别为 1209.7 、 $723.6 、 642.9 、 585.4 、 675.3 、 587.0 、 661.8$ 和 $569.0 \mathrm{~mm}$. 比较各种土地利用类型的蒸散发能力可以看出,水面 蒸发能力最大, 林地、灌丛和耕地的蒸散发能力次之, 草地、密灌丛和裸土的蒸散发能力较小. 总体而言, 双 源蒸散发能力计算模型能合理反映蒸散发物理机制,计算获得的流域蒸散发能力能充分反映下垫面的空间 异质性,适用于我国北方干旱半干旱区蒸散发能力的计算.

\section{4 日径流模拟}

本研究以空间分辨率为 $30 \mathrm{~s}$ 的栅格单元作为产流单元, 在数字流域平台的基础上, 将双源蒸散发能力计算 


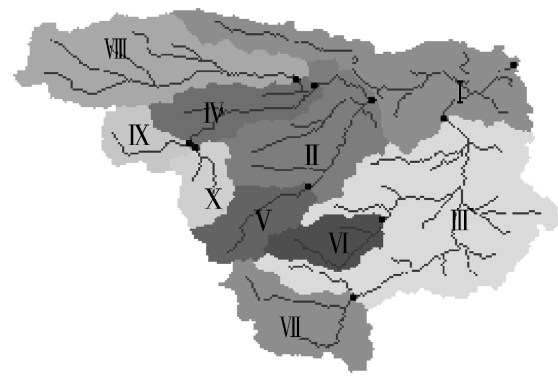

图 6 老哈河流域各子区域分布

Fig. 6 Distribution of sub-regions in the Laoha River catchment

模型与混合产流模型进行耦合, 以双源蒸散发能力计算模型计 算的截留蒸发、植被蒸腾能力和土壤蒸发能力取代蒸发血资料 作为混合产流模型的输人, 构建基于双源蒸散与混合产流的分 布式水文模型,对老哈河流域 $1970-1979$ 年的日径流过程进 行模拟.

2.4.1 参数率定方案 老哈河流域内共有 10 个水文站, 其中 小河沿站位于流域的出口,其余 9 个站均位于其上游, 集水面 积为 $582-8678 \mathrm{~km}^{2}$ (表 3). 按水文站控制的汇水区域将整个 研究区域化分为 10 个子区域 (图 6), 先率定上游源头子区域 的水文参数, 然后将上游水文站的实测流量作为下游子区域 人流, 逐个对子区域进行参数率定, 以避免径流累积误差使得 下游子区域的参数偏离其物理意义.

表 3 老哈河流域内水文站的地理信息

Tab. 3 Geographic information of hydrological stations in the Laoha River catchment

\begin{tabular}{ccccccccccc}
\hline 地理信息 & 小河沿 & 赤峰 & 太平庄 & 新店 & 锦山 & 小城子 & 甸子 & 初头朗 & 兴巨德 & 杨树湾子 \\
\hline 集水面积 $\left(\mathrm{km}^{2}\right)$ & 18599 & 8678 & 7720 & 5580 & 906 & 803 & 1643 & 3009 & 850 & 582 \\
子区域序号 & I & II & III & I & V & VI & VII & VIII & IX & X \\
子区域面积 $\left(\mathrm{km}^{2}\right)$ & 2201.2 & 2190.5 & 5277.5 & 1138.8 & 906 & 803 & 1643 & 3009 & 850 & 582 \\
\hline
\end{tabular}

模型参数在老哈河流域空间变异性明显, 以流域平均蓄水容量 $(W M)$ 的分布而言, 其值在 III 、 V、VI、VII 子区域上较小, 在 I、II 和 IV 子区域上较大. III V V、VI、VII 子区域位于老哈河流域东南源头区, 降水量较大、 气候湿润, 其多年平均降水量分别为 447.4、506.4 、510.7 和 $571.1 \mathrm{~mm}$, 且地处山区土层较薄, 而 I、II 和 IV 子 区域位于老哈河流域西北下游区, 降水量较小、气候干燥, 其多年平均降水量分别为 379.7、402.8 和 $411.1 \mathrm{~mm}$, 并且地处平原土层较厚 (图 6). 在湿润地区, 流域平均蓄水容量偏小, 容易蓄满, 在干旱地区, 流域 平均蓄水容量偏大, 不易蓄满, 这符合参数 $W M$ 的物理意义.

流域平均最大下渗能力 $f_{0}$ 是混合产流模型中最敏感的参数, 它控制着地表径流比例和洪峰流量. $f_{0}$ 大 值区分布在 V、VI、VII 子区域, 这些子区域位于老哈河流域西南高海拔的源头区, 地表植被覆盖较好, 林地覆 盖率较高 (表 4$). f_{0}$ 的小值区主要分布在老哈河流域的下游, 植被覆被类型以耕地和草地为主. 植被覆盖能

表 4 各子区域水文模型日模参数的率定结果 *

Tab. 4 Calibrated parameter values for the daily runoff simulation within sub-regions

\begin{tabular}{ccccccccccccc}
\hline 参数 & I & II & III & IV & V & VI & VII & VII & IX & X & 参数范围 & 离势系数 \\
\hline$W M(\mathrm{~mm})$ & 200 & 200 & 140 & 200 & 140 & 140 & 140 & 170 & 180 & 180 & $140-200$ & 0.15 \\
$W U M(\mathrm{~mm})$ & 40 & 40 & 20 & 40 & 20 & 20 & 20 & 30 & 20 & 20 & $20-40$ & 0.33 \\
$W L M(\mathrm{~mm})$ & 90 & 90 & 80 & 90 & 80 & 80 & 80 & 90 & 90 & 90 & $80-90$ & 0.06 \\
$B$ & 0.22 & 0.22 & 0.18 & 0.21 & 0.35 & 0.16 & 0.3 & 0.22 & 0.3 & 0.25 & $0.16-0.35$ & 0.23 \\
$B X$ & 0.77 & 0.77 & 0.3 & 0.77 & 0.31 & 0.25 & 0.8 & 0.75 & 0.76 & 0.7 & $0.25-0.8$ & 0.35 \\
$f_{0}(\mathrm{~mm} / \mathrm{h})$ & 6 & 6 & 8 & 6 & 29 & 30 & 20 & 15 & 6 & 6 & $6-30$ & 0.71 \\
$f_{\mathrm{c}}(\mathrm{mm} / \mathrm{h})$ & 1.4 & 2.4 & 3 & 3 & 3 & 3 & 3.2 & 3.5 & 2.2 & 3.5 & $1.4-3.5$ & 0.22 \\
$k$ & 0.4 & 0.4 & 0.2 & 0.4 & 0.3 & 0.27 & 0.2 & 0.36 & 0.45 & 0.47 & $0.2-0.47$ & 0.27 \\
$k g$ & 0.97 & 0.96 & 0.89 & 0.96 & 0.9 & 0.84 & 0.84 & 0.99 & 0.96 & 0.95 & $0.84-0.99$ & 0.06 \\
$c$ & 0.12 & 0.15 & 0.15 & 0.12 & 0.1 & 0.1 & 0.12 & 0.1 & 0.092 & 0.092 & $0.092-0.15$ & 0.18 \\
$K E(\mathrm{~h})$ & 24 & 24 & 24 & 24 & 24 & 24 & 25 & 21 & 24 & 24 & $21-25$ & 0.04 \\
$X E$ & 0.44 & 0.42 & 0.3 & 0.4 & 0.15 & 0.35 & 0.28 & 0.2 & 0.26 & 0.14 & $0.14-0.44$ & 0.35 \\
\hline
\end{tabular}

* WUM 为上层蓄水容量; $W L M$ 为下层蓄水容量; $W M$ 为流域平均蓄水容量 $; B$ 为蓄水容量曲线指数; $B X$ 为下渗能力分布 曲线指数; $f_{0}$ 为流域平均最大下渗能力; $f_{\mathrm{c}}$ 为流域平均稳定下渗能力; $k$ 为下渗能力衰减系数; $k g$ 为地下水日消退系 数; $c$ 为深层蒸散发折算系数; $K E$ 和 $X E$ 均为马斯京干参数. 
降低雨滴的冲击作用, 植物根系腐烂增加了土壤中的空隙, 使雨水滞留有利于下渗, 因此较好的地表植被覆 盖有利于增加下渗量,参数 $f_{0}$ 将会偏大, 由此可见 $f_{0}$ 在老哈河流域上的空间分布是符合其物理规律的.

2.4 .2 结果分析 基于双源蒸散与混合产流的分布式水文模型对老哈河流域日径流模拟结果精度较高(表 5 ), 率定期的确定性系数除 1973 年外,其余各年均在 0.80 以上,各年的径流相对误差均在 $\pm 20 \%$ 以内; 验证 期的确定性系数均大于 0.84 , 径流相对误差绝对值均小于 $10 \%$.

\section{表 5 小河沿(兴隆坡)站日径流模拟精度*}

Tab. 5 Performance of distributed hydrological for daily runoff simulation in Xiaoheyan (Xinglongpo) station

\begin{tabular}{|c|c|c|c|c|c|c|c|c|c|c|c|c|}
\hline \multirow{2}{*}{ 年份 } & \multicolumn{8}{|c|}{ 率定期 } & \multicolumn{4}{|c|}{ 验证期 } \\
\hline & 1970 & 1971 & 1972 & 1973 & 1974 & 1975 & 1976 & $1970-1976$ & 1977 & 1978 & 1979 & $1977-1979$ \\
\hline$D C$ & 0.85 & 0.88 & 0.83 & 0.78 & 0.89 & 0.87 & 0.85 & 0.85 & 0.84 & 0.85 & 0.95 & 0.94 \\
\hline $\operatorname{Bias}(\%)$ & 5.12 & 10.04 & 13.32 & 1.13 & -0.69 & -15.9 & -11.55 & -0.61 & 9.28 & 0.57 & 4.43 & 4.52 \\
\hline
\end{tabular}

* DC 为确定性系数 DC, Bias 为径流相对误差.

以 1979 年为例, 比较了小河沿 (兴隆坡) 水文站实测和模拟日流量过程, 两者径流变化趋势十分一致, 拟合程度高(图 7). 这也表明本文构建的分布式水文模型对老哈河流域的径流模拟较为适用.

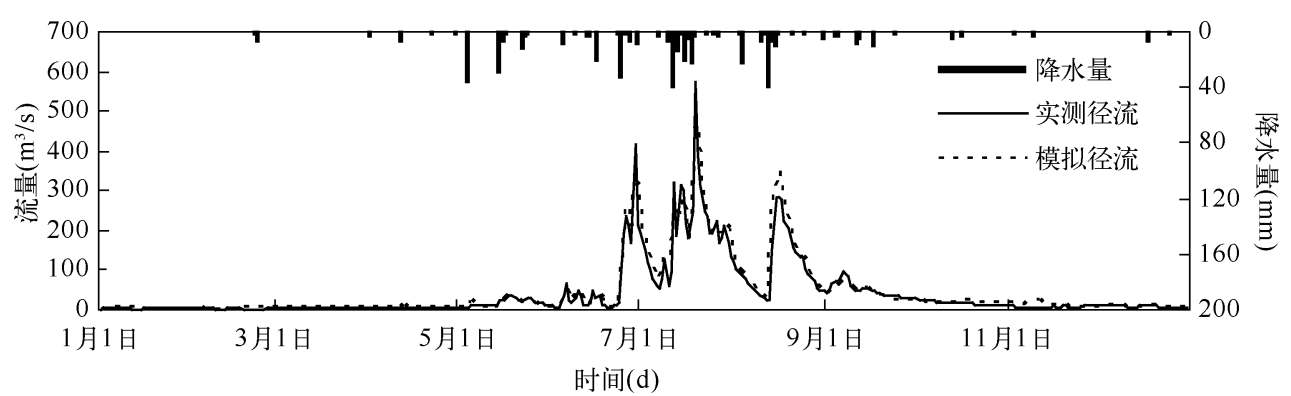

图 7 老哈河流域小河沿水文站 1979 年实测和模拟日流量过程比较

Fig. 7 Comparison of observed and simulated daily runoff at Xiaoheyan hydrological station within the Laoha River catchment in 1979

\section{3 结论}

通过上述研究, 可以得到以下几点结论: (1) 双源蒸散发能力计算模型估算的日蒸散发能力与蒸发血. 日资料在时间尺度上有较好的相似性和一致性，且二者定量关系受到了植被类型和季节的影响；(2) 基于 双源蒸散与混合产流的栅格型分布式水文模型在率定期和验证期日径流模拟精度较高,各子区域率定的参 数空间分布符合其本身的物理意义和规律, 表明该模型适用于该地区的水文过程模拟.

本文构建的分布式水文模型能充分考虑流域植被覆盖的空间差异性对蒸散发能力的影响,并合理地表 征了植被物侯特征、生理特性以及地形等因素对流域蒸散发、产流和汇流过程的影响,为研究变化环境下水 文响应以及植被一水文一气候关系等提供了有力工具,但该模型还存在下述不足:(1) 模型本身有待改进,例 如需合理地考虑坡地汇流的计算以及对模型中有关假设的有效性应作出评述等; (2) 需进一步与其他蒸散 发能力计算模型或分布式水文模型的结果进行比较, 以充分说明本研究模型的优越性.

\section{4 参考文献}

[ 1 ] Federer CA, Vörömarty C, Fekete B. Intercomparison of methods for calculating potential evaporation in regional and global water balance models. Water Resour Res,1996,32(7) : 2315-2321.

[ 2 ] Shuttleworth WJ. Evaporation, in Handbook of Hydrology. In: Maidment DR ed. New York: McGraw-Hill, 1993 : 10-20.

[ 3 ] Penman HL. Natural evaporation from open water, bare soil and grass. Proceedings of the Royal Society of London, 1948, 
A193: 120-145.

[ 4 ] Priestley CHB, Taylor RJ. On the assessment of surface heat flux and evaporation using large scale parameters. Monthly Weather Review, 1972,100: 81-92.

[ 5 ] Deardorff JW. Efficient prediction of ground surface temperature and moisture with inclusion of a layer of vegetation. J Geophys Res,1978,83 : 1889-1903.

[ 6 ] Dunn SM, Mackay R. Spatial variation in evapotranspiration and influence of land use on catchment hydrology. Journal of Hydrology, 1995 ,171 : 49-73.

[ 7 ] Stannard DI. Comparison of Penman-Monteith, Shuttleworth-Wallace, and modified Priestley-Taylor evapotranspiration models for wildland vegetation in semiarid rangeland. Water Resour Res,1993,29(5) : 1379-1392.

[ 8 ] Monteith JL. Evaporation and environment. Symposium of the Society for Experimental Biology,1965,19: 205-234.

[ 9 ] Shuttleworth WJ, Wallace JS. Evaporation from sparse crops-an energy combination theory. Quarterly Journal of the Royal Meteorological Society, 1985,111 : 839-855.

[10] Choudhury BJ, Monteith JL. A four-layer model for the heat budget of homogeneous land surface. Quarterly Journal of the Royal Meteorological Society,1988,144 : 373-398.

[11] Mo X, Liu S, Lin Z et al. Simulating temporal and spatial variation of evapotranspiration over the Lushi basin. Journal of Hydrology,2004,285 : 125-142.

[12] 袁 飞. 考虑植被影响的水文过程研究 [学位论文]. 南京: 河海大学, 2006: 23-47.

[13] Zhou MC, Ishidaira H, Hapuarachchi HP et al. Estimating potential evapotranspiration using Shuttleworth-Wallace model and NOAA-AVHRR NDVI data to feed a distributed hydrological model over the Mekong River basin. Journal of Hydrolo$g y, 2006,327:$ 151-173.

[14] 李春红. 基于数字流域的半湿润区产流计算方法比较研究 [学位论文]. 南京:河海大学,2003: 27-51.

[15] 胡春歧. 半干旱半湿润地区产流计算方法的研究. 水文情报预报学术交流会论文选集. 北京: 中国水利水电出版 社,1993: 57-62.

[16] Liu Xiaofan, Ren Liliang, Yuan Fei et al. Quantifying the effect of land use and land cover changes on green water and blue water in northern part of China. Hydrology and Earth System Science, 2009,13 : 735-747.

[17］翟家瑞. 常用水文预报算法和计算程序. 郑州：黄河水利出版社, 1995: 11-20. 